\title{
Seasonal variation in health exposure to PM-bound Polycyclic Aromatic Hydrocarbons in selected sport facility
}

\author{
Karolina Kuskowska ${ }^{1, *}$, Wioletta Rogula-Kozłowska ${ }^{1}$ \\ ${ }^{1}$ The Main School of Fire Service, Faculty of Civil Safety Engineering, 52/54 Slowackiego St., 01- \\ 629 Warsaw, Poland
}

\begin{abstract}
In this paper, for the one selected sport facility in Warsaw in heating and non-heating periods: 1 ) average concentration of 15 polycyclic aromatic hydrocarbons (PAHs) associated with respirable fraction of particulate matter $\left(\mathrm{PM}_{4}\right) ; 2$ ) health hazards from the $\mathrm{PM}_{4}$-bound PAHs; 3 ) $\mathrm{PM}_{4}$-bound PAHs origin are described. PM samples were collected for 10 days of June and 10 days of November simultaneously inside and outside of the sports hall and next were analysed in term of PAHs content. Obtained results allowed to calculate selected indicators of cumulative exposure to the $\mathrm{PAH}$ mixture and the specific diagnostic ratios for individuals compounds from the PAHs group which indicate origin of PAHs. It has been shown that the exposure of sports hall users to $\mathrm{PM}_{4}-$ bound PAHs is significantly higher in heating than non-heating season. It also confirm that fossil fuels and biomass combustion in heating period in Warsaw have a strong influence on the level of health exposure to PAH mixture both outdoor and inside of the buildings.
\end{abstract}

\section{Introduction}

Research into the human health impact of airborne particulate matter (PM) shows that breathing through the nostrils causes the deposition of the majority of inhaled PM particles with aerodynamic diameter larger than $2.5 \mu \mathrm{m}$ [1-3]. Differently situation is during physical exercise when oral breathing usually occurs what causes bypassing of the natural filtration mechanisms in the upper parts of the respiratory system. Moreover, breath is deeper and more frequently during intense exercise [4-7]. It results an increase the amount of particles, not only fine, i.e. with aerodynamic diameters smaller than $2.5 \mu \mathrm{m}$, but also coarse particles, which reaching the deeper regions of the respiratory system, i.e. trachea, bronchi or alveoli $[6,7]$. Therefore, athletes who have a higher oxygen requirements and a larger minute tidal volume than physically inactive people seem to be a particular exposure group [7]. Nevertheless, the exposure is determined not only by the PM concentration in general but also by other factors such as: concentration of microbial contaminants, mass size distribution of PM, concentration of gaseous pollutants, i.e. nitrogen oxides, sulphur oxides, volatile organic compounds, carbon dioxide, concentrations of some PM-bound substances,

\footnotetext{
*Corresponding author: kkuskowska@sgsp.edu.pl
} 
like toxic metals or polycyclic aromatic hydrocarbons [8-9]. In the health risk assessment, the last parameter is especially important, due to the proven carcinogenic, mutagenic and/or toxic potential of some compounds from the PAH group [10-12].

The paper presents concentrations of 15 most common and the most often examined compounds of the PAH group (acenaphthene (Acn), anthracene (An), benzo[a]anthracene $(\mathrm{BaA})$, benzo[a]pyrene $(\mathrm{BaP})$, benzo[b]fluoranthene $(\mathrm{BbF})$, benzo[k]fluoranthene $(\mathrm{BkF})$, benzo[g, h, i]perylene (BghiP), chrysene (Ch), dibenzo[a]anthracene (DahA), fluoranthene (Flt), fluoren (Flu), phenanthrene (Phen), naphthalene (Na), pyrene (Pyr) and indeno[1,2,3cd]pyrene (IP)) [12-13] associated with respirable fraction of PM $\left(\mathrm{PM}_{4}\right)$ in one of the Warsaw sports halls. $\mathrm{PM}_{4}$-bound PAH have been analyzed in this paper because PAHs in respirable fraction of PM has higher penetration abilities than PAHs in coarse particles and consequently can determine inhalation exposure to PAH in general [6-7].

\section{Material and methods}

\subsection{Description of the sampling sites}

Samples of $\mathrm{PM}_{4}$ were collected inside and outside of the sports hall of the Sports and Recreation Centre (OSiR) of the Targówek district located in Warsaw at 25 Ossowskiego Street (52॰16'19 N, 21॰02'42 E). The OSiR hall has been operating since 2000. It is a twolevel multi-purpose facility designed for playing handball, basketball, indoor football, volleyball and table tennis. On the ground floor there is a sports hall with dimensions of $44 \mathrm{~m} \times 24 \mathrm{~m}$ and sanitary rooms. The upper floor is an auditorium for 200 people and office rooms. The floor of the hall is a parquet. The building uses only gravity ventilation. During weekday the hall is used by students of the nearby school and during weekends trainings of amateurs take place there. The immediate vicinity of the hall is: on the south side - a singlestorey residential building, on the north side - school complex buildings, on the west - the tartan football field and on the east - the Ossowskiego street closed during periods of measurements due to works related to the construction of the subway. About 100 meters in a straight line to the west runs St. Vincent street characterized by the highest traffic volume in the region (according to data from the 2016 Association of Warsaw Metropolitan Transport (SISKOM), about 1900 cars/hour). In addition, from the north-east side, low buildings with individual furnaces dominate.

\subsection{PM sampling}

$\mathrm{PM}_{4}$ samples were collected simultaneously inside and outside of the sports hall during two periods: 05/06/2017-21/06/2017 (non-heating period) and 06/11/2017 - 22/11/2017 (heating period). The average daily time of the PM sampling was 480 minutes. The PM concentration were examined by gravimetric method (PN-91/Z-04030/06, PN-91/Z0430/05) with using two GilAir 3 aspirators and glass filters (Cat. No. GF1-025, diameter $25 \mathrm{~mm}$ ). Inside the hall the PM samples were collected at a height of approx. $1.5 \mathrm{~m}$ from the ground level and at a distance of not less than $2 \mathrm{~m}$ from the trainers (area on which the classes were held). Outside the hall PM sampler was placed on the windowsill from the west side of the building at a height of $5 \mathrm{~m}$. from the ground. The procedures of conditioning and weighing of clean filters and PM samples were the same as in [14]. 


\subsection{PAH analysis}

For the purpose of isolating PAHs adsorbed by the $\mathrm{PM}_{4}$ collected on the filters two-stage extraction was conducted. The extracts were subjected to chromatographic analysis. PAH analysis was carried out using high performance liquid chromatography (HPLC) using a Thermo Scientific Surveyor Finningan chromatograph with a UV/Vis detector $(25 \mu \mathrm{l}$ injection loop, C18 chromatography column (Hypersil Green PAH $5 \mu \mathrm{m}, 250$ x $4.6 \mathrm{~mm}$ )). The mobile phase was a solution of acetonitrile and water $(60: 40 \mathrm{v} / \mathrm{v})$ with the flow rate $1.2 \mathrm{~cm}^{3} / \mathrm{min}$. The detection was carried out with a $254 \mathrm{~nm}$ wavelength. The identification of compounds was made on the basis of the compliance of the retention time with the standard. The determinations were made on the basis of calibration curves determined separately for each compound. For calibration purposes, a mixture of 15 PAHs (610 PAH Calibration Mix A manufactured by RESTEK) was used. The limit of detection for each compound was $0.35 \mathrm{ng} / \mathrm{ml}$.

\subsection{Data analysis}

The level of exposure of persons actively using sports hall to hazards from the $\mathrm{PM}_{4}$-bound PAHs was expressed by indicators of the exposure: carcinogenicity (CEQ), mutagenicity (MEQ) of the PAH mixture; contribution of carcinogenic PAHs in the total concentration of PAH mixture calculated according to the methodology presented in [12] and carcinogenic potentials of compounds from the PAH group (CP) calculated according to the method described in [15] separately for the heating and non-heating season. Moreover, in order to determine the origin of $\mathrm{PAH}$ in the heating and non-heating season specific diagnostic ratios (DR) were calculated [12]. The research described in this paper is a continuation of research into PAH concentrations in sports facilities carried out by the author of this publication in the period from December 2016 to January 2017 described in [16].

\section{Results}

The concentration of 15 compounds from the group of polycyclic aromatic hydrocarbons (PAH) related to $\mathrm{PM}_{4}$ in the indoor and outdoor air of the sports hall during the heating and non-heating season is shown in Table 1 . In general, higher PAH concentrations were recorded during the heating season than in the non-heating season. The ratio of PAH concentrations ( $\Sigma \mathrm{WWA}$ ) in the winter and summer seasons was 3.5 inside the hall and around 3 in atmospheric air in its surroundings. The research shows that concentrations of $\mathrm{PM}_{4}$-bound PAHs were about 4 times higher inside than outside the hall.

Table 1. The sum of the average concentration of $\mathrm{PM}_{4}$-bound $15 \mathrm{PAHs}\left(\mathrm{PAH}, \mathrm{ng} / \mathrm{m}^{3}\right)$ including carcinogenic PAH $(\Sigma \mathrm{PAH}$ carc $)$ in indoor and outdoor air of the Sports and Recreation Centre in the period $5^{\text {th }}$ June $-21^{\text {st }}$ June 2017 (non-heating season) and $6^{\text {th }}$ November $-20^{\text {th }}$ November 2017 (heating season).

\begin{tabular}{|c|c|c|c|c|}
\hline & \multicolumn{2}{|c|}{ Non-heating season } & \multicolumn{2}{|c|}{ Heating season } \\
\hline & Indoor & Outdoor & Indoor & Outdoor \\
\hline $\mathbf{P M}_{4}\left[\mu \mathrm{g} / \mathrm{m}^{3}\right]$ & 16 & 34 & 34 & 33 \\
\hline$\Sigma P A H\left[n g / m^{3}\right]$ & 131 & 36 & 461 & 106 \\
\hline$\Sigma \mathbf{P A H}_{\text {carc }}\left[\mathrm{ng} / \mathrm{m}^{3}\right]$ & 94 & 18 & 227 & 77 \\
\hline$\Sigma \mathbf{P A H}_{\text {carc }} / \mathbf{\Sigma P A H}$ & 0.7 & 0.5 & 0.5 & 0.7 \\
\hline
\end{tabular}

Analysis of the mass contribution of individual $\mathrm{PM}_{4}$-bound PAHs in the total concentration of PAHs ( $\mathrm{PAH})$ in the indoor air of the hall showed that in the non-heating 
season the largest share belonged to BaP (70\%) and BghiP (15\%). In heating season, the largest mass contribution had $\mathrm{BaP}$ and $\mathrm{Pyr}$ and in both cases it was $43 \%$ (Figure 1). In the atmospheric air the highest mass contribution in the $\mathrm{PM}_{4}$-bound $\Sigma \mathrm{PAH}$ concentrations had Pyr (10\%) and $\mathrm{BaP}(6 \%)$ in the non-heating season; in the heating season additionally Phen $(20 \%)$. Based on the individual contributions of individual PAHs compounds in $\mathrm{PAH}$ inside and outside of the hall it should be noticed that the presence of some PAHs inside the hall (in particular BaP, Pyr, BghiP in the non-heating season and $\mathrm{BaP}, \mathrm{Pyr}$ and DahA in the heating season) may result from the inflow of ambient air. Because the dynamics of changes in the indoor air is lower than in the atmospheric air, it cannot be excluded that the remaining components of the PAH mixture inside the hall do not come from the atmospheric air, which flowed to the hall a few days before the measurements.

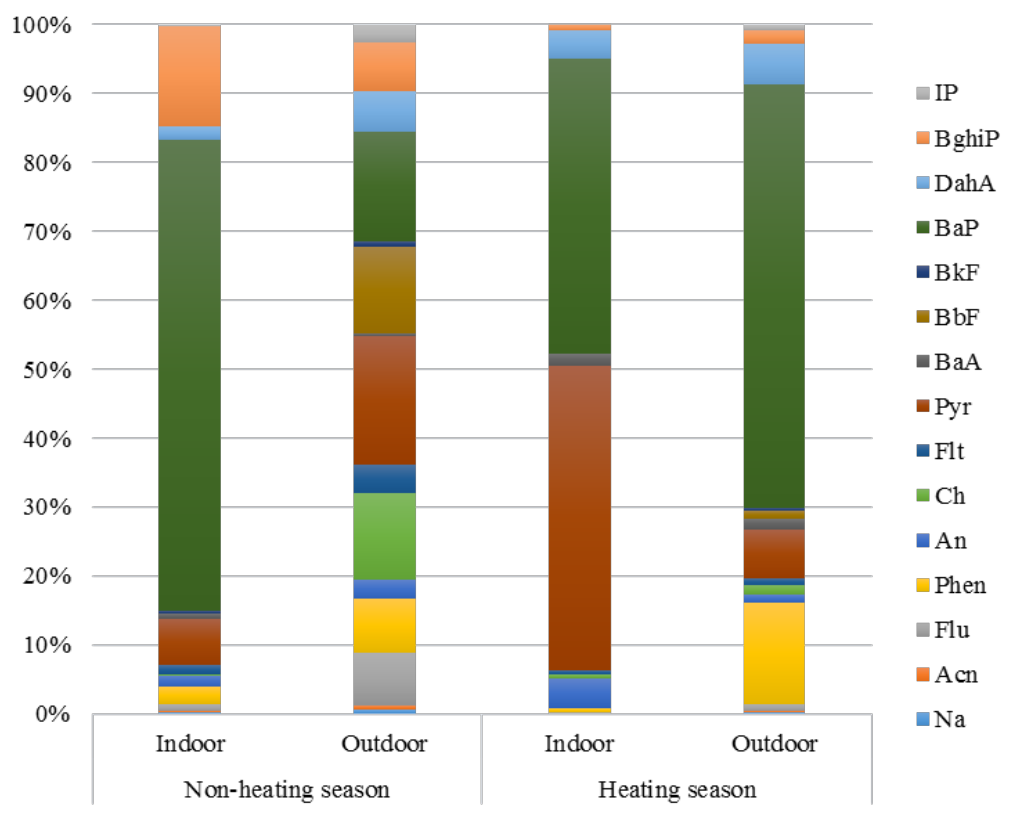

Fig 1. The mass contribution of the individual compounds of PAHs mixture in the $\Sigma \mathrm{PAH}$ in the indoor and outdoor air of the sports hall in non-heating (5-21/06/017) and heating (6-22/11/2017) season.

The health risk of exposure to the PAH mixture in the sports hall expressed by the indicators of the carcinogenicity (CEQ) and mutagenicity (MEQ) (Figure 2) were significantly higher for the PAH mixture in the indoor air than in the atmospheric air. In the non-heating season CEQ in the indoor air reached the average value $102 \mathrm{ng} / \mathrm{m}^{3}$ while in heating season was even higher and reached $292 \mathrm{ng} / \mathrm{m}^{3}$. Also, the values of the MEQ indicator in both the heating and non-heating season were several times higher inside the hall than in its surroundings. The calculated values of indicators of exposure for the PAH mixture in the sports hall are not only higher than analogous for ambient air in its surroundings but they are also several dozen times higher than the values recorded in urban areas in Europe, including Polish cities [17] or in school rooms in Gliwice and Warsaw [18]. The average mass share of the sum of carcinogenic compounds, i.e. $\mathrm{BaA}, \mathrm{BaP}, \mathrm{BbF}$, $\mathrm{BkF}, \mathrm{Ch}, \mathrm{DahA}, \mathrm{IP}[19]$ in the average ambient concentration of PAH $\left(\Sigma \mathrm{PAH} \mathrm{Harc}_{\mathrm{cos}} / \Sigma \mathrm{PAH}\right)$ in the indoor air was $72 \%$ in the non-heating season and $49 \%$ in the heating season, while outside it was $51 \%$ in the non-heating season and $72 \%$ in the heating season (Table 1). 


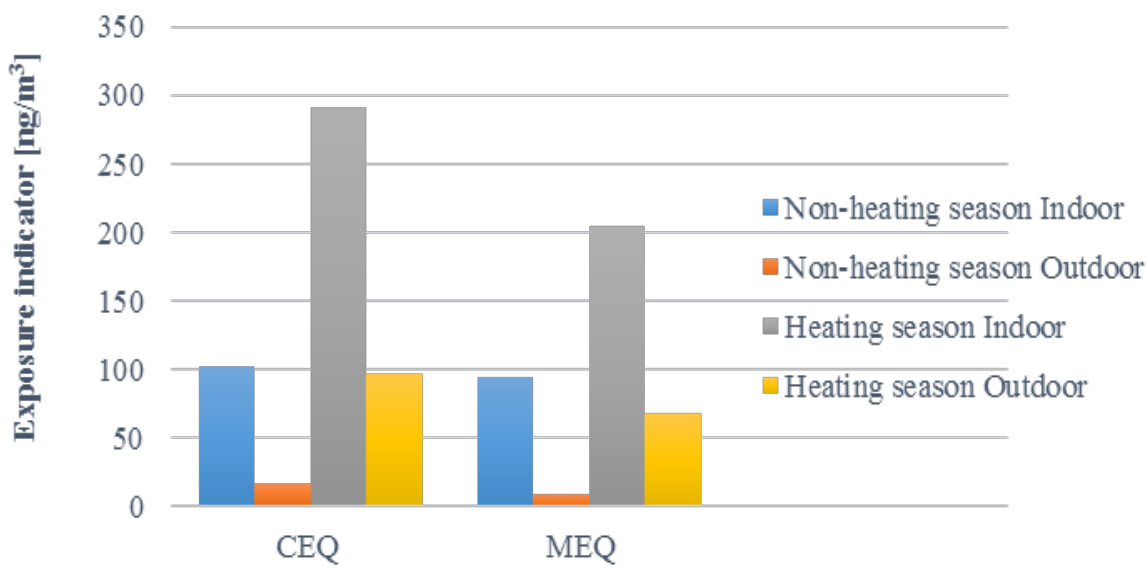

Fig 2. Mean values of the risk indicators (CEQ, MEQ) $\left[\mathrm{ng} / \mathrm{m}^{3}\right]$ for $\mathrm{PM}_{4}$-bound $\mathrm{PAH}$ in the indoor and outdoor air of the sports hall in non-heating (5-21/06/2017) and heating (6-22/11/2017) season.

In both analyzed measurement seasons (heating and non-heating) the highest percentage share in the formation of carcinogenic exposure to the PAH mixture $(\mathrm{CP}$, carcinogenic potential [15]) in both samples taken inside the hall and in its surroundings belonged to Pyr and $\mathrm{BaP}$ (Figure 3). CP for Flu, Phen, An, Flt, DahA, BghiP ranged from several to several percent, and the share of $\mathrm{Na}, \mathrm{Acn}, \mathrm{BaA}, \mathrm{BkF}$, IP was insignificant. The origin of $\mathrm{PM}_{4}-$ bound PAHs in the studied locations (inside and outside the sports hall) can be assessed by analyzing of diagnostic ratios (Table 2$)$. The values of the $\mathrm{Phen} /(\mathrm{Phen}+\mathrm{An})$ ratio at the level of approx. 0.65 indicate diesel fuel combustion as the main source of $\mathrm{PM}_{4}$-bound $\mathrm{PAHs}$ in the indoor and outdoor air in the summer season. BbF and BkF relation $>0.5$ and IP and BghiP relation $<0.4$ are also characteristic for this source of PAHs. In connection with the above, it can be stated that also in the winter season, the non-exhaust traffic related emissions is the source of PAHs both inside and outside the hall. However, the Phen/(Phen + An) ratio, which in the heating season reached a value $>0.76$ indicates that other source of PAHs in this period is the combustion of coal. $\mathrm{BaA} /(\mathrm{BaA}+\mathrm{Ch})$ values close to 0.5 also indicate that in addition to non-exhaust traffic related emission, the combustion of coal and coke is the PAHs source in the indoor and outdoor air of the hall in the cold season (Table 2). 


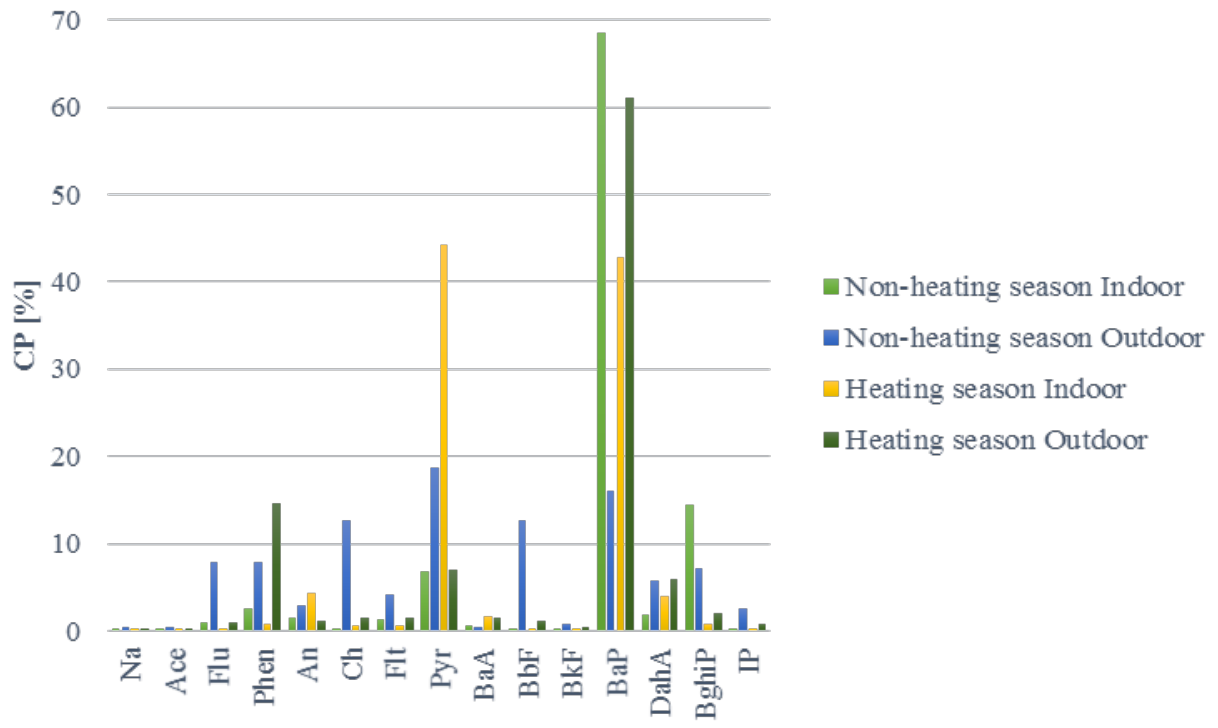

Fig 3. Caricinogenic potential represented by each compound of the PAH mixture calculated on the basis of 8-h series of concentrations of individual PAHs in the indoor and outdoor air of the sports hall in non-heating (5-21/06/017) and heating (6-22/11/2017) season.

Table 2. PAH diagnostic ratios for the indoor and outdoor air of the sports hall in non-heating (5-21/06/2017) and heating (6-22/11/2017) season.

\begin{tabular}{|c|c|c|c|c|c|}
\hline \multirow{2}{*}{ Diagnostic ratio } & \multicolumn{2}{|c|}{ Non-heating season } & \multicolumn{2}{|c|}{ Heating season } & \multirow{2}{*}{ Source of PAHs [12] } \\
\hline & Indoor & Outdoor & Indoor & Outdoor & \\
\hline Flu/(Flu+Pyr) & 0.13 & 0.30 & 0.001 & 0.13 & $<0.5-$ petrol emissions \\
\hline An/(An+Phen) & 0.37 & 0.27 & 0.85 & 0.07 & $\begin{array}{l}>0.1 \text { - petrogenic; } 0.24 \text { - coal } \\
\text { burning }\end{array}$ \\
\hline Phen/(Phen+An) & 0.63 & 0.73 & 0.15 & 0.93 & $\begin{array}{l}0.65 \text { - diesel; }>0.7 \text { - pertoleum; } \\
0.76 \text { - coal; }\end{array}$ \\
\hline Flt/(Flt+Pyr) & 0.20 & 0.22 & 0.02 & 0.21 & $<0.4$ - unburned petroleum; \\
\hline Flt/Pyr & 0.20 & 0.22 & 0.02 & 0.21 & $\begin{array}{l}\sim 0.6-\text { non-exhaust traffic related } \\
\text { emissions; }\end{array}$ \\
\hline $\mathrm{BaA} /(\mathrm{BaA}+\mathrm{Ch})$ & 0.82 & 0.03 & 0.76 & 0.49 & $\begin{array}{l}0.2-0.35 \text { - coal burning; }>0.35- \\
\text { non-exhaust traffic related } \\
\text { emissions; } 0.5-\text { coal } / \text { coke } \\
\text { burning; }\end{array}$ \\
\hline $\mathrm{BaP} /(\mathrm{BaP}+\mathrm{Ch})$ & 1.00 & 0.56 & 0.99 & 0.98 & 0.5 -diesel ; 0.73 - gasoline \\
\hline $\mathbf{B a A} / \mathbf{B a P}$ & 0.01 & 0.03 & 0.04 & 0.02 & 1- diesel ; \\
\hline IP/(IP+BghiP) & 0.02 & 0.26 & 0.05 & 0.27 & $0.2-0.5$ - petroleum combustion; \\
\hline IP/BghiP & 0.02 & 0.34 & 0.06 & 0.37 & $<0.4-$ petroleum combustion; \\
\hline $\mathrm{BbF} / \mathrm{BkF}$ & 0.50 & 15.39 & 0.62 & 2.69 & $>0.5-$ diesel; \\
\hline BaP/BghiP & 4.74 & 2.23 & 57.08 & 31.63 & $\begin{array}{l}>1.25-\text { coal/coke; }<0.6-\text { non- } \\
\text { exhaust traffic related emissions }\end{array}$ \\
\hline Pyr/BaP & 0.10 & 1.16 & 1.03 & 0.12 & $\begin{array}{l}\sim 10-\text { diesel; } \sim 1-\text { petroleum } \\
\text { combustion }\end{array}$ \\
\hline
\end{tabular}




\section{Conclusions}

Exposure to the impact of the PM-bound PAH mixture in the sports hall is large and regardless of the measurement season is greater than exposure to PM-bound the $\mathrm{PAH}$ mixture in the atmospheric air at the same time. Nevertheless, PAH concentrations related to the respirable fraction of PM during the heating period are about 3 times higher than $\mathrm{PAH}$ concentrations in the non-heating season. The health exposure to the PAH mixture is determined particularly by the high content of $\mathrm{BaP}$ and $\mathrm{Pyr}$, which have the highest carcinogenic potentials among PAHs analyzed in indoor and outdoor air of the sports hall. The values of diagnostic ratios confirm that the main source of the PAH mixture inside and outside the sports hall are combustion of fuels (gasoline, diesel oil, crude oil) during the summer and winter season and additionally combustion of coal, coke and wood in the heating season. It also proves that the quality of indoor air in terms of the $\mathrm{PM}_{4}$-bound PAHs concentration is determined by the atmospheric air quality flowing from the surroundings.

The article was realized within the statutory research no. S/E 422/8/16/17 co-financed by funds of the Ministry of Science and Higher Education provided to the Faculty of Civil Safety Engineering of The Main School of Fire Service in 2017. The research described in the article is part of the research done as part of Karolina Kuskowska's PhD dissertation "Analysis of hazards related to physicochemical properties of dust in the air of selected sports facilities" under supervision of Prof Wioletta RogulaKozłowska at The Main School of Fire Service, Faculty of Fire Safety Engineering (Warsaw).

\section{References}

1. J. Londahl, J. Pagels, E. Swietlicki, J.C. Zhou, M. Ketzel, A. Massling, M. Bohgard, Aerosol Sci. 37, 9 (2006)

2. W. Rogula-Kozłowska, J.S. Pastuszka, E. Talik, Prace i studia 80, 111 (2011)

3. K. Ki-Hyun, K. Ehsanul, K. Shamin, Environ. Int. 74, 136 (2015)

4. C.C. Daigle, D.C. Chalupa, F.R. Gibb, P.E. Morrow, G. Oberdörster, M.J. Utell, M.W. Frampton, Inhal. Toxicol. 15, 6 (2003)

5. V. Niinimaa, P. Cole, S. Mintz, Resp. Physiol. 42, 1 (1980)

6. M.K. Sracic, J. Aerosol Sci. 99, 54 (2016)

7. W. Wojtasik, A. Szulc, M. Kołodziejczyk, A. Szulc, J. Educ. Health Sport 5, 10 (2015)

8. J. Hendiger, P. Ziętek, M. Chludzińska, Wentylacja $i$ klimatyzacja. Materiaty pomocnicze do projektowania (Venture Industries, Warszawa, 2009)

9. H. Recknagel, E. Sprenger, E.R. Schramek, Kompendium wiedzy. Ogrzewnictwo, klimatyzacja, ciepła woda, chłodnictwo (Omni Scala, Wrocław, 2008)

10. D.S. Jyethi, P.S. Khillare, S. Sarkar, Environ. Sci. Pollut. Res. 21, 366-378 (2014)

11. K.H. Kim, S.A. Jahan, E. Kabir, R.J.C. Brown, Environ. Int. 60, 71-80 (2013)

12. W. Rogula-Kozłowska, In : Synergic Influence of Gaseous, Particulate, and Biological Pollutants on Human Health ed. J.S. Pastuszka (CRC Press, 2015)

13. PN-Z-04030-06:1991

14. A. Dvorská, G. Lammel, J. Klánová, Atmos. Environ. 45, 420-427 (2011)

15. J.M. Dalgao-Saborit, C. Stark, R.M. Harrison, Environ. Int. 37, 383-392 (2011)

16. K. Kuskowska, W. Rogula-Kozłowska, P. Rogula-Kopiec, E3S Web Conf. 28, 01020 (2018)

17. B. Kozielska, W. Rogula-Kozłowska, P. Rogula-Kopiec, I. Jureczko, Ecol. Eng. 49, 25-32 (2016)

18. W. Rogula-Kozłowska, B. Kozielska, G. Majewski, P. Rogula-Kopiec, W. Mucha, K. Kociszewska, J. Environ. Sci. 64, 235-244 (2018)

19. IARC, A Review of Human Carcinogens: Arsenic, Metals, Fibres, and Dusts. Monographs on the Evaluation of Carcinogenic Risks to Humans (IARC, 2012) 